\title{
Parental perception on nebulized medication and potential reasons for off-label usage of dexamethasone in children from Romania
}

\author{
Mihai Craiu1,2, Valentina Daniela Comanici11,2, Iustina Violeta $\operatorname{Stan}^{1,2}$ \\ 1"INSMC Alessandrescu - Rusescu", Bucharest, Romania \\ 2"Carol Davila" University of Medicine and Pharmacy, Bucharest, Romania
}

\begin{abstract}
Background and aim. In the last decade a significant increase of nebulized medication usage has been documented in Romania. Authors are aiming to describe parental and physician's change of perspective regarding nebulized medication in the new era of online communication and education.

Material and methods. Two different questionnaires were posted in a large and representative group (more than 60,000 followers) of Romanian parents and physicians, Virtual Children's Hospital („Spitalul Virtual de Copii").

Results. More than 4,000 answers were submitted. 94.4\% responders confirmed using at least once wetnebulized medication in children. A particular aspect documented was dexamethasone off-label usage via nebulizer in $67.8 \%$ children. Additional $7 \%$ of responders confirmed that they received an indication to nebulize a normal saline suspension with dexamethasone phosphate for parenteral usage, but they didn't follow the indication and used an approved treatment.

Conclusions. Upon our knowledge this is the first large study on nebulized dexamethasone in Romanian literature. $95 \%$ of Romanian children receive nebulized medication. Nebulizer is regarded by parents as a simple and friendly tool that can solve virtually all issues related to airway diseases in our country. $75 \%$ of children that received nebulized medication had a prescription for off-label use of dexamethasone.
\end{abstract}

Keywords: dexamethasone, nebulized, child, off-label

\section{BACKGROUND AND AIM OF STUDY}

In the last decade a significant increase of nebulized medication usage has been documented in Romania. 94.4\% of Romanian parents that answered an online questionnaire (1) stated usage of nebulized medication in their children, at least once.

Online access to health-related issues is easier than ever. Many Romanian parents go online, for information, even before medical consultation. $74 \%$ urban patients went online or to Social media resources, regarding health and health care issues (2). Unfortunately most of the accessed resources weren't scientifically solid, many users going for blogs or general forum information. This particular approach of Romanian patients and parents can probably explain the huge increase of nebulized medication usage in the last decade.

Authors are aiming to describe parental and physician's change of perspective regarding nebulized medication in the new era of online communication and education.

\section{MATERIAL AND METHODS}

Two different questionnaires were posted in a large and representative group (more than 60,000 followers) of Romanian parents and physicians, Virtual Children's Hospital (SVC - „Spitalul Virtual de Copii"). 
These questionnaires were generated via Google forms documents and were delivered online for a limited duration, around two weeks each.

First questionnaire entitled „Inhaled medication via nebulizer, in children" was distributed both to parents and physicians. There were five questions and document was posted in SVC in July 2017. Questions were:

1. Have you ever used nebulized medication in your child/patient?

2. Have you ever used inhaled corticosteroids (Flixotide nebules/Fluticasone propionate, Pulmicort respules/Budesonide)?

3. Have you ever used off-label dexamethasone phosphate solution (from ampules produced for injectable use) via nebulizer?

4. How long have you used nebulized medication in a given episode?

5. What other nebulized medication have you provided to your patient/child?

Second questionnaire entitled „Education for inhalation technique in children with respiratory diseases" was distributed only to parents and included six questions. This second document was posted in SVC in November 2017. Only first three questions are relevant for current study:

1. Have you ever used inhaled medication for your child?

2. What type of medication was used more often?

3. What type of inhaled medication had you ever used in your child?

\section{RESULTS}

First questionnaire generated 1,682 answers and second one 2,366. Most of responders in first questionnaire answered to first question: $98.93 \%(1,664$ people). $94.4 \%$ responders confirmed using at least once wet-nebulized medication in children. 1,659 people answered second question (98.63\%). Only $64.8 \%$ stated that they have used at least once inhaled corticosteroids (ICS). A particular finding was the high proportion (35.2\%) of responders that stated using off-label only systemic steroids for nebulization. Third question was answered by 1,663 people (98.87\%). A particular aspect documented was dexamethasone off-label usage via nebulizer in $67.8 \%$ children. Additional $7 \%$ of responders (117 people) confirmed that they received an indication to nebulize normal saline suspension with dexamethasone phosphate, but they didn't follow the indication and used an approved treatment. Only $25.1 \%$ (418 people) stated that they have never used dexamethasone for nebulization.

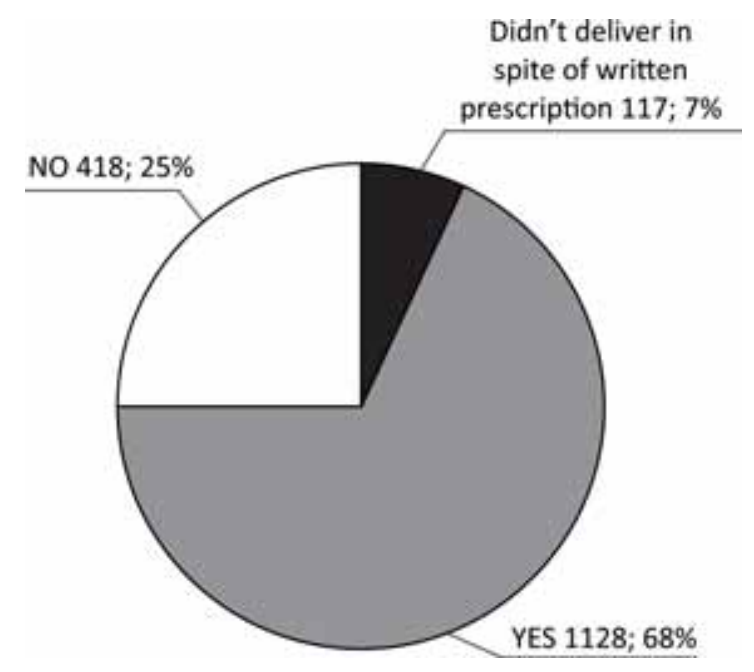

FIGURE 1. Answer distribution for third question „Have you ever used off-label dexamethasone phosphate solution (from ampules produced for injectable use) via nebulizer?"

Fourth question generated 1,588 answers (94.41\%). $1213(76.4 \%)$ stated a limited use of nebulized steroids, below one week, 271 (17.1\%) up-to two weeks and $104(6.5 \%)$ answered that they have used chronic nebulization of steroids, more than one month, irrespective type of steroid (ICS or systemic) (see Fig. 2).

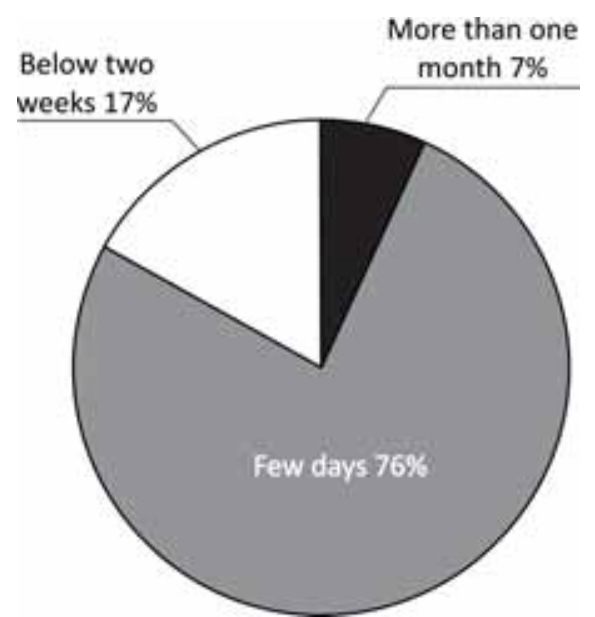

FIGURE 2. Answer distribution for fourth question „How long have you used nebulized medication in a given episode?"

Fifth question was answered by 1,252 people $(74.43 \%)$ with 110 versions of answers, most of them citing Albuterol (Ventolin 0.5\% solution for nebulizer). Further analysis of this answer is beyond the scope of this paper, but proves that many patients received medication for reversible airflowlimitating diseases.

First question from second questionnaire was answered by all parents, $96.5 \%$ stating that they delivered inhaled medication to their children at least 
once. Second question was answered by 2,286 parents $(96.62 \%)$. 1,738 (76\%) used only wet nebulized drugs, 345 (15.1\%) used pressurized metered dose inhalers (pMDI's) with spacer and 181 (7.9\%) pMDI's without spacer.

\section{DISCUSSIONS}

There are few papers on information sources regarding inhaled or nebulized medication. Many patients, or their parents, search online information on nebulized medication and technique (3). Frequently urban patients in Romania use unapproved documentation sources regarding health issues, $31 \%$ are asking friends in Social Media, 32\% use blogs and $74 \%$ use general forum information (2). This switch of patient's perspective upon patientphysician communication has evolved slowly during the last two decades (4). This process has a significant trend in Romania and is partially responsible for self-medication and noncompliance.

Major strength of our paper is the large number of answers (more than 4,000) from a large and representative group of Romanian parents „Spitalului Virtual de Copii". Main weakness was restricting research to parents that use Social Media. This group of parents represent three quarters of urban population when health issues are involved (2).

A potential explanation for off-label use of dexamethasone injectable ampules via a jet-nebulizer could be attributed to constant shortage in Flixotide nebules. Although in license number 7843/2006/0102 for dexamethasone phosphate injectable solution (5) there is no statement regarding inhalator route for delivery, such an approach was used in two thirds of Romanian children receiving wet nebulized medication. National Drug Agency (ANMDM) in third chapter „How to use?" is stating: „Drug will be delivered by medical personnel. Dose will be given by intramuscular or intravenous injection or by a slow intravenous infusion. Dose will be calculated by your physician according to diagnosis and severity. Dose can be modified in relation with clinical response (...). In some cases drug can be delivered locally (intraarticular, periarticular, local infiltration of inflamed tissues), by a special injection technique".

In this official document there are no data regarding nebulized delivery nor dose indications for such an indication.

Should be emphasized that besides those parents that used nebulized dexamethasone $(67.8 \%)$ there is a group of $7 \%$ that refused off-label use and asked for approved medication.
Where does such an off-label approach comes from? Are there any literature data on inhaled dexamethasone? Performing a PubMed search with "dexamethasone" and „nebulized" search-words we will retrieve 88 papers (6). If we will eliminate papers on oral or injectable dexamethasone and papers related to other nebulized drugs than dexamethasone, we will end up with only 8 papers (714). Only two were published from 2000 onwards. Only four papers are documenting the drug type involved and this is dexamethasone sodium phosphate.

Only one paper published in 1995 (13) addresses dexamethasone sodium phosphate efficacy (dose $1.5 \mathrm{mg} / \mathrm{kg}$ ) compared with oral prednisone (dose 2 $\mathrm{mg} / \mathrm{kg}$ ) in treatment of asthma exacerbations. This paper is stating similar efficacy of inhaled dexamethasone, compared with prednisone, in Emergency Department, for mild and moderate asthma exacerbations in children 1 up to 17 years old. This singular statement should be regarded cautiously because a Cochrane meta-analysis from 2012 is stating that ,there is insufficient evidence that ICS therapy can be used in place of systemic corticosteroid therapy when treating acute asthma" (15).

Another double-blind, placebo controlled trial regarding nebulized dexamethasone is evaluating efficacy in treating children with moderate croup episodes presented in Emergency Room (11). Drug used is also dexamethasone sodium phosphate. Treatment with nebulized dexamethasone results in clinical improvement within 4 hours but no decrease in hospitalization rates. Given the infectious complications (in 2 of 55 patients) and the absence of evidence for a sustained clinical effect authors do not recommend that patients with croup be treated with nebulized dexamethasone.

In another paper for similar indication (croup presented in Emergency Room) $160 \mu \mathrm{g}$ nebulized dexamethasone, is compared with oral dexamethasone $(0.6 \mathrm{mg} / \mathrm{kg})(8)$. Authors of this placebo-controlled study are stating that oral dexamethasone has better effects in treating croup patients with moderate severity both in symptom resolution and reducing failure rate. Only $11.76 \%$ of oral dexamethasone treated patients had to be reevaluated compared with $29.67 \%$ of nebulized dexamethasone and $32.95 \%$ of placebo patients.

In Sitzman and Fiechtner's review (9) of various steroid types used in croup treatment is mentioned dexamethasone. Authors conclude that dexamethasone is efficient and safe in layngotracheitis patients and should be delivered orally or intramuscu- 
lar. There are no data on nebulized dexamethasone efficacy and no dosage for this route is provided.

There is a paper regarding geriatric patients (14) with asthma. Nebulizing dexamethasone in seniors with Parkinson's disease and dementia, where other treatment options seem difficult, has modest results.

Two of these 8 papers do not have an abstract in PubMed $(10,12)$ and another is exploring stability of various solutions used to be nebulized in cystic fibrosis patients. There are no data on nebulized dexamethasone efficacy in these CF patients (7). Authors evaluate solution stability by mixing various drugs with $7 \%$ sodium chloride. Such an idea was explored in order to attempt a decrease of total daily time spent in nebulizing drugs for CF patients. Visual and turbidimetric testing was conducted to assess the compatibility of admixtures: acetylcysteine, albuterol, atropine, cromolyn sodium, dexamethasone, glycopyrrolate, ipratropium, metaproterenol, sodium bicarbonate, terbutaline, and tobramycin. Current European Consensus on inhaled medication and inhalation devices for lung diseases in patients with cystic fibrosis do not comment on inhaled dexamethasone (28).

$23^{\text {rd }}$ edition of Taketomo's „Pediatric \& Neonatal Dosage Handbook" is documenting only oral or injectable (intramuscular or intravenous) as proven routes for systemic delivery. There are no mentions on inhalation of dexamethasone (16).

Where this local approach of nebulizing dexamethasone does came from? Is there a product that has been used for such a purpose? There was long time ago a dexamethasone product intended for inhalator usage, Auxiloson (dexamethasone 21-isonicotinate).

A PubMed search about this drug finds 13 papers published between 1968 and 1981, las tone published by Romanian researchers. Popescu and Basacopol (17) are stating that beclomethasone (Becotide) and dexamethasone (Auxiloson) improved clinical status in $80 \%$ of patients of two asthma groups without any other details.

Unfortunately there are only few pediatric papers on this product. The only one with available abstract is Manicatide's paper from 1980 (18). Author presents a positive response in steroid-dependent children with decrease or stopping of systemic medication. One can speculate that steroid sparing mechanism involved could be attributed to increased bioavailability of nebulized dexamethasone that generates systemic effects. Because most of Auxiloson treated children retained Cushingoid features even after ceasing treatment with oral ster- oids. The other two Auxiloson papers regarding children with asthma do not have available abstract. They were published in 1979 in Czech language and in 1972 in German $(19,20)$.

There is a single recent paper that cites Auxiloson used in human patients (21). It presents dexamethasone 21-isonicotinate use in accidental toluene di-isocyanate exposure. Favorable effect in this exposure is also documented for beclomethasone but unfavorable for theophylline.

Unfavorable safety profile of dexamethasone 21-isonicotinate compared with other ICS (in Girard's paper from 1975 (22) Auxiloson was compared with beclomethasone propionate) and low efficacy were reasons for human use discontinuation.

Now this product (dexametazona 21-izonicotinat) is used only in veterinary medicine, papers documenting rather modest effects in horse (23) or positive in a murine asthma model (29).

What could be done in order to decrease this huge off-label use of dexamethasone? Question seems pertinent because there are precise statements regarding steroid use in Romanian Pediatrics Society guidelines for acute laryngitis (special note on dexamethasone in moderate/severe cases of croup (24)) or in asthma exacerbations (25) or in recurrent wheezing flare-ups (26). In spite of Romanian Guidelines that discourage nebulizing steroids in acute bronchiolitis episodes (30) in our study we have found that such an approach is very common. Steroid use is deferred in acute bronchiolitis, irrespective route (31). Maybe a more vigorous approach on off-label use in children, or in human subjects in general, should be implemented and presented in medical conferences and medical media.

Because of the actual behavior of Romanian parents that go first online and later they approach their physician, a Social Media education tool should be developed. Authors have produced an educational space called Virtual Asthma Hospital (, Spitalul Virtual de Astm”) in the portal of Mother and Child Health Institute (INSMC "Alessandrescu-Rusescu"). Using online parental education and telemonitoring increased medication compliance and decreased unscheduled emergency visits in children with asthma (27).

\section{CONCLUSIONS}

Upon our knowledge this is the first paper from Romania that approaches off-label use of nebulized dexamethasone. 
Excessive use of nebulized medication, for every trivial disease of upper airway, with inadequate drugs (systemic steroids instead of inhaled ones) and for inappropriate duration (rather episodic than continuous, as controller medication) is a real phenomenon in Romania, that should not be neglected. Most parents perceive nebulized medicine as an ac- ceptable option for more invasive treatment approaches. Many physicians consider nebulizing dexamethasone as a correct approach, $75 \%$ of children from our study receiving a medical prescription. $7 \%$ of parents after reading about this subject asked for a safer treatment option.

\section{Conflict of interest: none declared} Financial support: none declared

\section{REFERENCES}

1. Comanici V.D., Stan I.V., Craiu M. Off-label use of nebulized corticosteroids in pediatric practice. Pneumologia 2017; 66(3):163.

2. Anonymous. Medic ONE in ICEE.fest site - http://www.iceefest.com/ news/healthcare-in-the-digital-era-romanian-patients-point-of-viewresearch-by-medic-one-presented-for-the-first-time-at-iceehealth-2017/ (accessed in 26.11.2017)

3. Rosenzweig D., Nickels A.S. \#Asthma \#Inhaler: Evaluation of visual social media depictions of inhalers and spacers. J Allergy Clin Immunol Pract. 2017 May 19 doi: 10.1016/j.jaip.2017.04.029. (Epub ahead of print)

4. Hoencamp E. 'Yes doctor, no doctor': what do patients want from you? Acta Psychiatr Scand. 1999;100(5):319-20

5. Anonymous. Dexametazona fosfat in National Drug Agency site (ANM) https://www.anm.ro/__PRO/PRO_7843_29.12.06.pdf (accessed in 27.11.2017)

6. Anonymous. "dexamethasone nebulized" in PubMed site https://www. ncbi.nlm.nih.gov/pubmed/?term=dexamethasone+nebulized (accessed in 26.11.2017)

7. Fox L.M., Foushee J.A., Jackson D.J. et al. Visual compatibility of common nebulizer medications with $7 \%$ sodium chloride solution. Am J Health Syst Pharm. 2011;68(11):1032-5.

8. Luria J.W., Gonzalez-del-Rey J.A., DiGiulio G.A. et al. Effectiveness of oral or nebulized dexamethasone for children with mild croup. Arch Pediatr Adolesc Med. 2001;155(12):1340-5.

9. Sitzman S.J., Fiechtner H.B. Treatment of croup with glucocorticoids. Ann Pharmacother. 1998;32(9):973-4.

10. Adelman A. Treatment of croup with nebulized dexamethasone. J Fam Pract. 1996; 43(1):19-20.

11. Johnson D.W., Schuh S., Koren G. et al. Outpatient treatment of croup with nebulized dexamethasone. Arch Pediatr Adolesc Med. 1996; 150(4):349-55.

12. Singhi S. Steroids in acute asthma: oral or nebulized? Indian Pediatr. 1996;33(3):262-3.

13. Scarfone R.J., Loiselle J.M., Wiley J.F. 2nd. et al. Nebulized dexamethasone versus oral prednisone in the emergency treatment of asthmatic children. Ann Emerg Med. 1995;26(4):480-6.

14. Hoffman N.B., Laucka P.V. Dexamethasone aerosol use in an asthmatic nursing-home patient with Parkinson's disease and dementia. DICP. 1990;24(7-8):707-8.

15. Edmonds M.L., Milan S.J., Camargo C.A. Jr. et al. Early use of inhaled corticosteroids in the emergency department treatment of acute asthma. Cochrane Database Syst Rev. 2012 Dec 12; 12:CD002308. doi: 10.1002/14651858.

16. Anonymous Dexamethasone (systemic) in Pediatric \& Neonatal Dosage Handbook, Taketomo CK, Huriburt Hodding J, Kraus DM (eds). 23th ed LEXICOMP, APhA (American Pharmacists Association), 2017:532-5.

17. Popescu C., Basacopol A. (Corticotherapy of bronchial asthma, using dosed aerosols). Rev Ig Bacteriol Virusol Parazitol Epidemiol Pneumoftiziol Pneumoftiziol. 1981;30(4):225-30.

18. Manicatide M.A., Nicolaescu V.V., Stroescu V. et al. Dexamethasone-isonicotinate aerosol in the long-term treatment of steroid-dependent asthmatic children. Med Interne. 1980; 18(2):203-10.

19. Zapletal A., Spicak V., Zbojan J. et al. (Effect of a single inhalation of dexamethasone-21-isonicotinate (Auxiloson) on the obstruction of respiratory pathways in childhood asthma). Cesk Pediatr. 1979; 34(7):399-404.

20. Braatz $\mathrm{E}$. (Inhalation therapy of the asthmatic syndrome using dexamethasone-21-isonicotinate (Auxiloson R) in children). Ther Ggw. 1972;111(3):389-98.

21. Fabbri L.M., Maestrelli P., Saetta M. et al. Airway inflammation during late asthmatic reactions induced by toluene diisocyanate. Am Rev Respir Dis. 1991;143(3 Pt 2):S37-8.

22. Girard J.P., VonInthen M.C., Heimlich E.M. Therapeutic index of steroid aerosols in asthma. A single-blind comparative trial of beclomethasone dipropionate vs dexamethasone isonicotinate. Acta Allergol. 1975;30(6):363-74.

23. Couetil L.L., Art T., de Moffarts B. et al. Effect of beclomethasone dipropionate and dexamethasone isonicotinate on lung function, bronchoalveolar lavage fluid cytology, and transcription factor expression in airways of horses with recurrent airway obstruction. J Vet Intern Med. 2006;20(2):399-406.

24. loniuc I. Laringita acută în Nanulescu M. (editor) Protocoale de diagnostic şi tratament în pediatrie, Bucharest: Editura Medicala Amaltea; 2017: 20-5

25. Tatar S. Astmul bronşic în Nanulescu M. (editor) Protocoale de diagnostic şi tratament în pediatrie, Bucharest: Editura Medicala Amaltea; 2017: 49-55.

26. Chereches-Panta P. Wheezingul recurent la copil in Nanulescu M (editor) Protocoale de Diagnostic si Tratament in Pediatrie, Editura Medicala Amaltea Bucuresti 2017; 56-9.

27. Craiu M., Stan I.V. Social Media education decreases unscheduled outpatients visits in paediatric asthma patients. Abstract in Arch Dis Child 2017;102 (Suppl2):A4-A4.

28. Heijerman H., Westerman E., Conway S. et al. For the Consensus Working group. Inhaled medication and inhalation devices for lung disease in patients with cystic fibrosis: A European consensus. Journal of Cystic Fibrosis 2009; 8:295-315.

29. Jungsuwadee P., Dekan G., Stingl G. et al. Inhaled dexamethasone differentially attenuates disease relapse and established allergic asthma in mice. Clin Immunol 2004; 110(1):13-21.

30. Man S. Bronşiolita acută în Nanulescu M. (editor) Protocoale de diagnostic si tratament în pediatrie, Bucharest: Editura Medicala Amaltea; 2017:26-31.

31. Ralston S.L., Lieberthal A.S., Meissner H.C. et al. Clinical Practice Guideline: The Diagnosis, Management and Prevention of Bronchiolitis in Pediatric Clinical Practice Guidelines and Policies. A Compendium of evidence-based Research for Pediatric Practice. $15^{\text {th }}$ ed; Elk Grove Village/American Academy of Pediatrics AAP; 2015:49-84. 